\title{
Assessment of Awareness on COVID-19 among Adults by Using an Online Platform: 26 Countries View
}

\author{
Kogila Palanimuthu ${ }^{1}$, Birhanu Gutu ${ }^{2}$, Leta Tesfaye ${ }^{3}$, BuliYohannis Tasisa ${ }^{4}$, \\ Yoseph Shiferaw Belayneh ${ }^{5}$, Melkamu Tamiru ${ }^{6}$, Desalegn Shiferaw ${ }^{7}$ \\ ${ }^{1}$ Assistant Professor, Department of Nursing, College of Medicine and health sciences, Dambi Dollo University, \\ Oromia, Ethiopia, ${ }^{2}$ Lecturer, Department of Public Health, College of Medicine and health sciences, Dambi Dollo \\ University, Oromia, Ethiopia, ${ }^{3}$ Assistant Professor, Department of Physics, College of Natural and Computational \\ sciences, Dambi Dollo University, Oromia, Ethiopia, ${ }^{4 \& 6}$ Assistant Professor, Department of Biology, College of \\ Natural and Computational sciences, Dambi Dollo University, Oromia, Ethiopia, ${ }^{5}$ Assistant Professor, Department \\ of Chemistry, College of Natural and Computational sciences, Dambi Dollo University, Oromia, Ethiopia, \\ ${ }^{7}$ Assistant Professor, Department of Public Health, College of Medicine and health sciences, Dambi Dollo \\ University, Oromia, Ethiopia
}

\begin{abstract}
A study was conducted to assess the awareness on covid-19 by using online platform among global community. The objectives were to assess the socio demographic characteristics, to determine the relationship between levels of awareness of COVID-19 with their selected demographic variables.

A global community based cross sectional study was conducted by internet survey design with 2857 respondents. Data were collected by online Google form, researcher administered a questionaries' awareness on COVID 19 through goggle link to the online platform and receive responses from the respondents,. The collected data was tabulated and analyzed. Descriptive and inferential statistics were used.

Researchers observed that $29.1 \%$ of the respondents reported high levels of awareness, $48.5 \%$ of the respondents reported moderate levels of awareness and $23.4 \%$ of the respondents reported low levels of awareness on COVID-19 respectively. It is very essential to create the awareness on COVID 19 among global population and protect the global community from deadly disease.
\end{abstract}

Keywords: Cognizance, COVID-19, Online Platform, Global Community.

\section{Introduction}

The coronavirus belongs to a family of viruses that may cause various symptoms such as pneumonia, fever,

\section{Corresponding Author:}

\section{Kogila Palanimuthu}

Assistant Professor, Department of Nursing, College of Medicine and Health Sciences, Dambi Dollo University (Government of Ethiopia), KellemWollega Zone,

Oromia, Ethiopia-260

e-mail:kogila@dadu.edu.et

Phone:+251946266424,

Whats app Number: 09791868988 breathing difficulty, and lung infection ${ }^{1}$. These viruses are common in animals worldwide, but very few cases have been known to affect humans.

The World Health Organization (WHO) used the term 2019 novel corona virus to refer to a coronavirus that affected the lower respiratory tract of patients with pneumonia in Wuhan, China on 29 December 2019²,3. The WHO announced that the official name of the 2019 novel coronavirus is coronavirus disease (COVID-19) ${ }^{4}$. And the current reference name for the virus is severe acute respiratory syndrome coronavirus 2 (SARSCoV -2$)^{5}$.

However, current treatment on COVID-19 worldwide has mainly focused on infection control, 
effective vaccine, and treatment cure rate (Dong et al. 2020; Wang et al. 2020), as countries worldwide have to work on reducing the transmission rate of COVID19 by creating awareness ${ }^{6-9}$. In this COVID-19 pandemic, timely access to accurate information can be the difference between life and death (UNICEF Ethiopia April 2020) ${ }^{10}$.

As COVID-19 is a pandemic communicable disease, few things are known about the infection and from day today new updates and all what we heard about the infection to date are liable to updates/modification as the epidemiological study of the disease is underway. The basic awareness on COVID-19 among the Global community is acceptable. Timely dissemination of information by the Ministry of Health, WHO, UNICEF are very use full for the general public on the COVID-19. Here we are utilizing the online platform to assess the cognizance on COVID-19 IN Global community ${ }^{6-10}$.

This study was conducted to determine the public response on Cognizance on COVID-19 by using online platform. This study surely helps the local, national and international organization to identify the awareness on COVID-19 and prevent further transmission

\section{Objectives:}

General Objective: The aim of this study is to assess the level of awarenesson COVID-19 by using online platform in Global community, 2020.

\section{Specific Objectives:}

1. To assess the respondents socio-demographic characteristics.

2. To determine the relationship between level of awareness of COVID-19with their selected demographic variables.

\section{Materials and Method}

Non-experimental evaluative approach was used.A community based cross sectional study internet survey design was adopted. The source population was all the stages of people across the global community during the study period. Person who satisfying the inclusion criteria such as age group 18 years and above were voluntarily participated in the study during the study period.

Sample Size Determination: The minimum sample size for online survey should be 100 , required sample size was based on the estimated response rate, and at the time of proposal presentation tentative sample size was 2000 respondents.

Sampling Procedure: Received 2857 responses from various parts of country, respondents who were responded by using voluntary response sampling technique. All the stages of peoples across the world ' 26 different countries' were participated in the study.

\section{Variables:}

\section{Dependent Variable:}

\section{- Awareness on COVID-19}

\section{Independent Variables:}

- Socio-demographic factors

Data collection instrument and Questionnaires development

The questionnaire was prepared by the researchers, there were socio demographic questionnaire and 15 awareness questions on COVID-19 with the sources adopted from WHO, UNICEF and NHS. The questionnaire was translated from English into Afan Oromo and Amharic again translated back in to English, and comparisons were made on the consistency of the three versions.

Data Collection Procedure: Data was instinctively collected by using online platform. Respondents were filled the Google form for basic details voluntarily and also given the online consent to participate in the internet survey followed by respondents were filled the awareness questionnaire on COVID 19. Once who were successfully complete and submit the Google form instantly received their score by given email ID.

Data Processing and Analysis: Data was copied from Google spread sheet filled questionaries' were checked manually for completeness and then coded. Entered and cleaned using Epidata version 3.11. Double entry made to minimize entry error and exported to SPSS version 23.0 for analysis. Descriptive analysis was used to describe the percentages and number distributions of the respondents by socio-demographic and socio economic characteristics. Inferential statistics like ' $t$ ' test and ANOVA test were used to analyze the data. PValue $<0.05$ was considered to be declared statistically significant. 


\section{Results}

The cross sectional study internet survey was carried out to assess the awareness on COVID-19 among peoples from worldwide. The total of 2857 respondents was participated from 26 countries from the throughout the world as denoted in Figure-1.

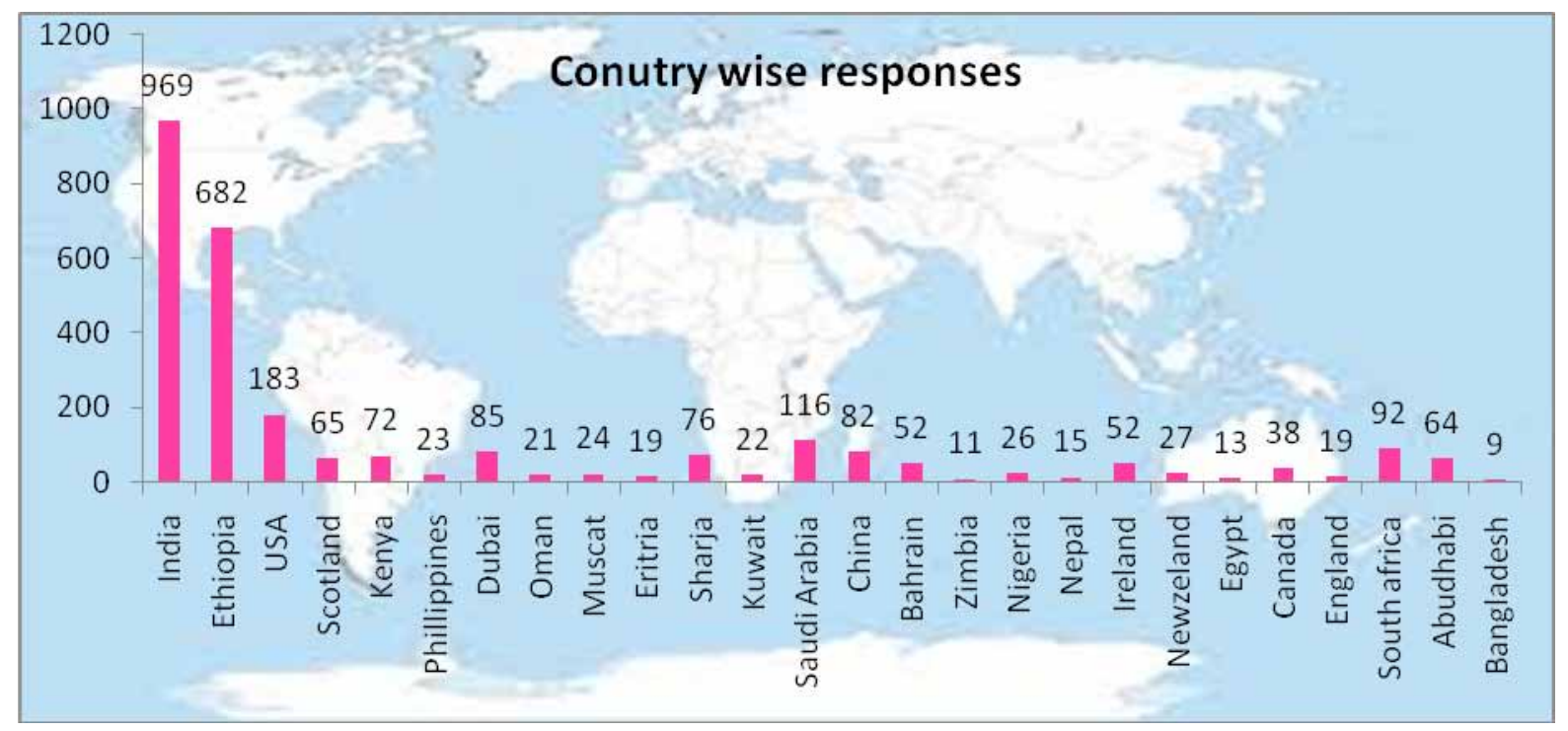

Figure-1: Country wise respondents on awareness on COVID19.

Socio demographic characteristics of the study respondents 1431 (50.05\%) were belongs to 18 -30 years, $756(26.46 \%)$ belongs $4031-40$ years, $417(14.60 \%)$ were $41-50$ years and very few reporte in the age groups above 51 years as $253(8.86 \%)$, in this $1236(43.26 \%)$ participants were male and 1621 (56.74\%) belongs to female.
Significant difference between male and female with respect to awareness on COVID19 among the respondents were presented in Table 1 and it is revealed that significance difference between male and female of respondents. Based on means core, the female respondents (1.843) have high level of perception on awareness than male respondents (1.656). Field of education is presented in Table 2 .

Table 1: t-test for significant difference between Male and Female with respect to Factors of awareness on COVID19 among the Respondents $\mathbf{N}=\mathbf{2 8 5 7}$

\begin{tabular}{|l|c|c|c|c|c|c|}
\hline \multirow{2}{*}{$\begin{array}{l}\text { Factors of perception on } \\
\text { COVID19 }\end{array}$} & \multicolumn{4}{|c|}{ Gender } & \multirow{2}{*}{ t-value } & \multirow{2}{*}{ P-value } \\
\cline { 2 - 5 } & \multicolumn{3}{|c|}{ Male } & \multicolumn{2}{c|}{ Female } & \\
\cline { 2 - 7 } & Mean & SD & Mean & SD & & \\
\hline Awareness & 1.6569 & 0.7272 & 1.8435 & 0.7943 & 2.849 & $0.005^{*}$ \\
\hline
\end{tabular}

Note:*Denotes significant at 5\%level

Since $\mathrm{P}$ value is less than 0.05 , null hypothesis is rejected at $5 \%$ level regard to Factors of awareness. Hence there is significance difference between male and female of respondents with regard to the Factors of awareness. Based on means core, the female respondents have high level of awareness on COVID 19 than male respondents.
Among 1236 (43.26) respondents were belongs to male, 1621 (56.74) respondents were belongs to female and their awareness on COVID 19 as follows: 832 (29.12), 1386 (48.51), 639 (22.36) low, moderate and high level of awareness respectively mentioned in Figure 2. 
Figure-2: Percentage of level of awareness on COVID19 among the Respondents.

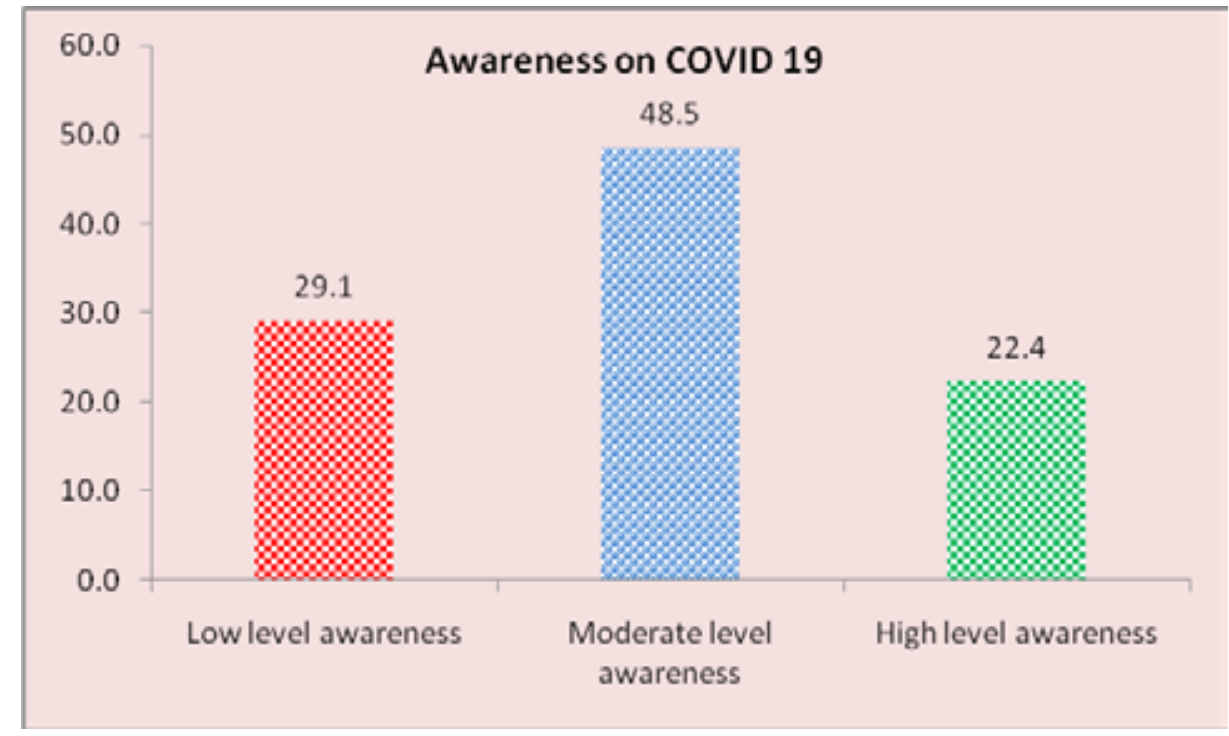

Table 2: ANOVA for significant difference among field of education with respect to Factors of awareness on COVID19 among Respondents

\begin{tabular}{|c|c|c|c|c|}
\hline Perception on COVID19 & Field of educatio & & F value & P value \\
\hline \multirow{5}{*}{ Awareness } & Paramedical & $1.98(0.78)$ & \multirow{5}{*}{2.499} & \multirow{5}{*}{$0.05^{*}$} \\
\hline & Arts and science & $1.86(0.76)$ & & \\
\hline & Law & $1.72(0.74)$ & & \\
\hline & Medical & $1.82(0.76)$ & & \\
\hline & Engineering & $1.79(0.74)$ & & \\
\hline
\end{tabular}

Note: The value within bracket refers to $\mathrm{SD}$, *denotes significant at $5 \%$ level

Table 3 Chi-square test for association between Gender and Level of awareness on COVID19 among respondents

\begin{tabular}{|c|c|c|c|c|c|c|}
\hline \multirow{2}{*}{ Gender } & \multicolumn{3}{|c|}{ Level of awareness } & \multirow{2}{*}{ Total } & \multirow{2}{*}{ Chi-square } & \multirow{2}{*}{$P$ value } \\
\hline & Low & Moderate & High & & & \\
\hline Male & $\begin{array}{c}356 \\
(42.8) \\
{[28.8]}\end{array}$ & $\begin{array}{c}591 \\
(42.6) \\
{[47.8]}\end{array}$ & $\begin{array}{c}281 \\
(44.0) \\
{[22.7]}\end{array}$ & $\begin{array}{c}1236 \\
(43.3) \\
{[100.0]}\end{array}$ & \multirow{3}{*}{8.028} & \multirow{3}{*}{$<0.005^{*}$} \\
\hline Female & $\begin{array}{c}476 \\
(57.2) \\
{[29.4]}\end{array}$ & $\begin{array}{c}795 \\
(57.4) \\
{[49.0]}\end{array}$ & $\begin{array}{c}350 \\
(54.8) \\
{[21.6]}\end{array}$ & $\begin{array}{c}1621 \\
(56.7) \\
{[100.0]}\end{array}$ & & \\
\hline Total & $\begin{array}{c}832 \\
(29.1) \\
{[100]}\end{array}$ & $\begin{array}{l}1386 \\
(48.5) \\
{[100]}\end{array}$ & $\begin{array}{c}639 \\
(22.4) \\
{[100]}\end{array}$ & $\begin{array}{c}2857 \\
100) \\
{[100]}\end{array}$ & & \\
\hline
\end{tabular}

Note: The value within() refers to column Percentage, The value within [ ] refers to row Percentage, *Denotes significant at 5\%level

Since $\mathrm{P}$ value is less than 0.05 , the null hypothesis is rejected at $5 \%$ level of significance. Hence concluded that there is association between Gender and Level of perception of awareness on COVID 19 among the respondents. Based on row percentage, $28.8 \%$ of male have low level of awareness, and $22.7 \%$ of male have high level of awareness whereas for female $29.4 \%$ belongs to low level of awareness and $21.6 \%$ belongs 
to high level of awareness. Hence majority of female respondents have high level of awareness and majority of males have low level of awareness as denoted in table 3 .

\section{Discussion}

The study was aimed to assess the awareness of on COVID 19. It was supposed that, this study provided important information and created overall image on awareness on COVID 19 in global community.

Present online study with 2857 responses from 26 different countries, 969 (33.9) were from India, 682 (22.9) responses from Ethiopia and responses from others countries as follows: USA 183 (6.4) Scotland 65 (2.3) Kenya 72 (2.5) Philippines 23 (0.8) Dubai 85 (3.0) Oman 21 (0.7) Muscat 24 (0.8) Eretria 19 (0.7) Sharjah 76 (2.7) Kuwait 22 (0.8) Saudi Arabia 116 (4.1) China 82 (2.9) Bahrain 52 (1.8) Zambia 11 (0.4) Nigeria 26 (0.9) Nepal 15 (0.5) Ireland 52 (1.8) Newzeland 27 (0.9) Egypt 13 (0.5) Canada 38 (1.3) England 19 (0.7) South Africa 92 (3.2) Abu Dhabi 64 (2.2) Bangladesh 9 (0.3)

In this 1236 (43.26) respondents were belongs to male, 1621 (56.74) respondents were belongs to female and their awareness on COVID 19 as follows: 832 (29.12), 1386 (48.51), 639 (22.36) low, moderate and high level of awareness respectively.

\section{Conclusion and Recommendations}

As the researchers observed and concluded that the present study of awareness on COVID 19 among global community was most of respondents exhibited moderate level of awareness on COVID 19, few had high level awareness and around $30 \%$ of the respondents are reported low level awareness. So, need to create the awareness on COVID 19 throughout the world with the aim to reduce the spread of infection and also protect the global community from deadly disease.

Recommendations- Many Awareness program, Pamphlets on COVID 19 are created by the organizations like WHO and circulated. But it can be possible only by the common public, responsible persons should take initiatives in each country like ambassador's to spread the awareness to each and every individuals of the world. It is very essential and important to create the awareness on pandemic disease to protect the global population from the Coronavirus and to lead healthy life.
Acknowledgement: The authors wholeheartedly wish to thank the university heads, Dambi Dollo University, Oromia, Ethiopia for their support for completing the research and also extending the sincere acknowledgement to all the respondents from different part of the world.

\section{Conflict of Interest: Nil}

Source of Funding: The Corresponding Author received funding from the Dambi Dollo University for conducting the this global community research through online platform and obtained Permission for authorship and Publication of this article.

Ethical Clearance: Official ethical clearance letter was received from Research and Technology Innovative directorate office, Dambi Dollo University. After receiving the official letter from the University, seeking for the consent and voluntary response from the participants followed by they were recruited as study participant. Confidentiality, anonymity and privacy were maintained by excluding the name and ID of study participants from the questionnaire. Autonomous was maintained for recruited respondents. Justice was maintained by voluntary response to select all the participants and veracity also maintained by truthfulness in each stage of the study.

\section{References}

1. WMHC. Wuhan Municipal Health and Health Commission's Briefing on the Current Pneumonia Epidemic Situation in Our City. 2020.

2. Li Q, Guan X, Wu P, Wang X, Zhou L, Tong Y, et al. Early transmission dynamics in Wuhan, China, of novel coronavirus-infected pneumonia. N Engl J Med. 2020.

3. Centers for Diseases Control and Prevention Coronavirus disease (COVID-19) outbreak (2020)

4. WHO. Novel Coronavirus, awareness-China. 2020.

5. Zhu N, Zhang D, Wang W, Li X, Yang B, Song J, et al. A novel coronavirus from patients with pneumonia in China, 2019. N Engl J Med. 2020.

6. WHO. Novel Coronavirus-Japan (ex-China). 2020.

7. Virological.org. Novel 2019 Coronavirus Genome 2020.

8. Fehr AR, Channappanavar R, Perlman S. Middle East respiratory syndrome: emergence of a 
pathogenic human coronavirus. Annu Rev Med.

2017; 68:387-99.

9. WHO. Statement on the second meeting of the International Health Regulations (2020)
Emergency Committee regarding the outbreak of novel coronavirus (2019-nCoV).

10. UNICEF, Coronavirus disease, awareness on COVID-19, (2020) 